Wendy Bottero (2004) 'Class Identities and the Identity of Class', Sociology, December 2004 vol. 38 no. 5, 985-1003. doi: 10.1177/0038038504047182

The final, definitive, version of this paper has been published in Sociology, 38/5/2004 by SAGE Publications Ltd. All rights reserved. (C).

It is available online at http://soc.sagepub.com/content/38/5/985.abstract

\title{
Class Identities and the Identity of Class
}

\section{Wendy Bottero}

\begin{abstract}
In rejecting both arguments of the 'death of class', and the increasingly minimalist positions of class traditionalists, a newer generation of class theorists have transformed the scope and analytical framework of class analysis: inflating 'class' to include social and cultural formations, reconfiguring the causal model that has underpinned class analysis, and abandoning the notion of distinct class identities or groups, focussing instead on individualized hierarchical differentiation. There are problems with transforming 'class' in this fashion, although the difficulty lies not in the departures from traditional class theory, but rather in what is retained. The uneasy relationship between older and newer aspects of 'class' within renewed class theory means the wider implications of inequality considered as individualized hierarchy (rather than as 'class') have not been fully explored. The debate on class identities (an important example of this new form of class analysis) illustrates these difficulties, and shows that issues of hierarchy extend well beyond issues of 'class'.
\end{abstract}

Key Words: class identities / hierarchy / social distance

\section{Introduction}

What does 'class' mean? Currently in class analysis we can see two distinct schools: one adopting an increasingly precise and contained approach to the meaning of 'class' (Goldthorpe, 1996; Marshall, 1997), whilst another group argue for an expanded and transformed class theory (Crompton, 1998; Crompton and Scott, 2000; Devine and Savage, 2000; Savage, 2000). The second school of thought has arisen in response to the perceived deficiencies of the first. The increasingly circumscribed claims of conventional class theory (Goldthorpe and Marshall, 1992) have been taken as sign of the theoretical exhaustion of class (Pahl, 1993). Even class proponents have noted its 'fragmentation' (Crompton, 1996), 'attenuation' (Morris and Scott, 1996) or 'minimalist' nature (Devine, 1998), and have called for a 'renewal' (Devine and Savage, 2000) of the class project, which would entail a 'wider and deeper' (Reay, 1998b) concept of class. It has been argued that what is required is a 'closer investigation of interests and identities' (Crompton and Scott, 2000: 5) giving rise to approaches based on 'social class analysis which, rather than seeking to distance themselves from the status concept, are premised upon the interrelationship of the "economic" and the "social"' (Crompton,1998: 119).

The proposed changes amount to a substantial broadening of the scope of class theory, yet inevitably raise questions about shifts in the meaning of 'class' itself. Crompton argues for 'plurality', with class understood as a diffuse 'organizing concept for the investigation of a 
wide range of issues associated with social inequality and social differentiation' (1998: 208). However, as Savage recognizes, 'pluralism' runs the risk of failing to address 'the deep conceptual, methodological and empirical uncertainties around the concept of class' (2000:

8). He insists that a 'lack of a clear intellectual basis for grounding culture and class' within traditional class theory, means that 'a culturalist approach to class analysis' (2000: 41) must abandon the traditional analytical framework of class analysis.

This article looks at recent work which has refashioned class analysis by placing a much greater emphasis on processes of culture, lifestyle and taste. Such work is too conceptually diverse to be regarded as a distinct 'school', but there are common themes. A renewed concern with issues of cultural identity has led to a 'focus on how cultural processes are embedded within specific kinds of socio-economic practices', exploring how inequality is routinely reproduced through both cultural and economic practices (Devine and Savage, 2000: 193, 196). Concurrently, there is an emphasis on the need for 'ethnographic examinations of how class is "lived" in gendered and raced ways to complement the macro versions that have monopolized our ways of envisaging social class for far too long' (Reay, 1998b: 272). A renaissance of empirical analysis combining qualitative and quantitative methods (most noticeably in the work of Mike Savage) has identified significant shifts in the composition and experience of the 'middle' and 'working-classes'; whilst recent qualitative work has reinvigorated ethnographic class research.

These new accounts represent a much needed redirection of class theory and research. However, the 'class' nature of such approaches must be questioned, since they dramatically enlarge the area under analysis, and also completely re-theorize it. New accounts question the centrality and distinctiveness of the 'economic', inflate 'class' to include social and cultural formations, and reconfigure the causal model that historically underpinned class analysis (class position leads to consciousness and action). Finally such approaches abandon the notion of distinct or cohesive class identities or groups, focussing instead on individualized hierarchical differentiation. The project of 'renewal' is so broad that it can be regarded as a general account of stratification itself, rather than as a specifically 'class' project (Bottero and Prandy, 2003).

Yet, ironically, the problem with transforming 'class' in this fashion lies in not the departures from traditional class theory, but rather in what is retained. Within new accounts of 'class' as cultural, individualized and implicit, there is still a tendency to look back to older versions of class theory - as collective, explicit and oppositional. The uneasy relationship of these different aspects of 'class' threatens to undo the considerable advances that have been made in theorizing processes of hierarchy and inequality. In particular, there has been a failure to acknowledge that if 'class' is to be conceived as individualized hierarchy this marks not simply a renewal of class theory, but rather a fundamental break with class categories. A reluctance to move beyond class categories has meant that the wider implications of inequality considered as hierarchy (rather than as 'class') have not been explored.

\section{Class Identities and Class Analysis}

A key issue for 'culturalist' class approaches is the embarrassing absence of clear-cut class identities, despite persisting inequality. Most commentators would accept Savage's argument that: 'Britain is not a deeply class conscious society, where class is seen as embodying membership of collective groups', for 'although people can identify as members 
of classes, this identification seems contextual and of limited significance, rather than being a major source of their identity and group belonging' (Savage, 2000: 40). The paradox of class is that 'the structural importance of class to people's lives appears not to be recognized by the people themselves. Culturally, class does not appear to be a selfconscious principle of social identity. Structurally, however, it appears to be highly pertinent' (p. xii).

Qualitative accounts indicate that people are reluctant to claim class identities, and adopt a 'defensive', 'hesitant', 'ambivalent' or 'ambiguous' attitude to class labels. People recognize the continuing salience of inequality, are willing to talk about class as a political issue, but refuse to place themselves 'within' classes, often explicitly dis-avowing class identities (Devine, 1992; Reay, 1998a, 1998b; Savage et al., 2001; Skeggs, 1997a). When confronted with questions about class issues, the respondents in such studies are often concerned to establish their own 'ordinariness' (Devine, 1992; Savage et al., 2001). Savage suggests that such responses are 'an indirect way of "refusing" class identity, and hence might be an indirect way of repudiating the entire "class" discourse altogether' (Savage, 2000: 35).

For many commentators there is an increasing divide between class conditions and the subjective perceptions and reactions to those conditions. Put simply, the connection between class location and cultural identity appears to have unravelled.

Class differences persist and have, in many respects, become sharper. However, these are far less directly reflected in distinct differences of social status, and so they are less directly reflected in sharp differences in attitude and outlook. Class consciousness - at least as conventionally understood - is no longer a central feature of contemporary class relations (Scott, 2000: 38). Beck famously sees contemporary society as both highly unequal and classlessly individualized (Beck, 1986: 88) and postmodern theorists claim this represents the death of class (Bauman, 1992; Crook et al., 1992; Pakulski and Waters, 1996), since widening material inequality no longer gives rise to class communities, and increasing individualization has destroyed any relationship that existed between economic position and cultural identity.

Traditional class analysts reject the 'death' of class but are themselves increasingly cautious about the extent to which class relations generate class identities (Goldthorpe and Marshall, 1992; Hout et al., 1993). Some have reworked class theory to dispense with the need for class identities at all. Goldthorpe's use of rational action theory, for example, allows him to argue that the same attitudes and beliefs have quite different consequences for those in differing class locations (Goldthorpe, 1996). Here it is the opportunities (and risks) presented by the different class locations of rationally acting individuals which constrains their behaviour, rather than variations in class cultures or attitudes.

The problem of class identities has created a curious symmetry. Just as postmodern writers have abandoned economic relations in their attempt to explain social identity, so class traditionalists have jettisoned social identity as a key component of class analysis. In both camps, the theoretical links between class location and social identity have been unpicked. As Savage notes, the result is a form of class analysis 'which makes little or no reference to 
claims about the salience of class cultures' and which he sees as a 'defensive attempt to shore up' class analysis (2000: 85 ) in the absence of clear-cut class identities.

For the newer generation of class theorists this response is simply too restrictive. Devine argues that the rational action approach is only possible because of the minimal way in which Goldthorpe defines class in terms of employment relations, rather than as 'collectivities of people who share identities and practices' (Devine,1998: 23). She criticizes Goldthorpe for focussing on the mobilization of economic resources in class reproduction, ignoring the influence of cultural and social resources on the 'micro processes by which classes are created and sustained over time and space' (1998: 33).

The new generation of class theorists attack both postmodern arguments that individualization undermines class identities, as well as the class defence which reformulates class analysis without class identities. They place issues of cultural identity at the heart of class theory, but recognize that such issues cannot be theorized from within traditional class analysis. Devine and Savage advocate a third alternative: 'culturalist class analysis', which addresses how 'in various settings of social life, processes of inequality are produced and reproduced routinely and how this involves both economic and cultural practices' (Devine and Savage, 2000: 196). This rejects the older analytical model in which economic class structure gives rise to status (or cultural) differences, to:

'...instead focus on how cultural processes are embedded within specific kinds of socioeconomic practices' (Devine and Savage, 2000: 194).

Fusing economic and cultural elements, this new form of class theory no longer requires class identities to form in a distinct and explicit manner. Instead:

'What establishes the relationship between class and culture (i.e., what establishes the classed nature of cultural dispositions) is not the existence of class consciousness, or the coherence or uniformity of a distinct set of cultural dispositions. Rather, the relationship is to be found in the way in which cultural outlooks are implicated in modes of exclusion and/or domination' (Devine and Savage, 2000: 195).

People do not have to explicitly recognize class issues, or identify with discrete class groupings, for class processes to operate. All that is required is for specific cultural practices to be bound up with the reproduction of hierarchy. The emphasis is not on the development (or not) of class consciousness, but rather on the classed nature of particular social and cultural practices. In new class theory: 'class cultures can be usefully viewed as modes of differentiation rather than as types of collectivity', where 'class' processes operate through individualized distinction rather than in social groupings (Savage, 2000: 102).

Rather than abandon class as a form of identity, such authors have instead abandoned the old model of class, fundamentally rethinking how class location is bound up with social identity. Individualization does not entail the death of class, but rather a shift in how class operates, for 'while collective class identities are indeed weak, people continue to define their own individual identities in ways which inevitably involve relational comparisons with members of various social classes', representing 'the reforming of class cultures around individualized axes' (Savage, 2000: xii). 


\section{Dis-identification and New Meanings of 'Class'}

The newer generation of theorists recognize that the failure of class identities is a problem for class analysis, but refuse to see in lay denials of class the failure of class processes. Rather, the absence of class identities is re-characterized as evidence of class, albeit 'class' in a transformed state. Dis-identification does not undermine class theory, because disidentifications are the result of class processes.

Skeggs, for example, argues that whilst the women in her working-class sample 'dissimulate from class, their dissimulations are produced from it' (Skeggs,1997a: 94). Drawing on Bourdieu's (1984) account of the relational nature of class cultures (where middle-class constructions of 'respectability' are partly organized around not being 'working-class', consequently devaluing and stigmatizing working-class culture), Skeggs argues that the 'pathologization' of working-class women means that women shrink from claiming workingclass identity. A parallel account is offered by Reay (1998a), and such studies relate female working-class dis-identification to the fact that working-class identity is a 'spoiled identity' for women. Similarly whilst, historically, male working-class identity has had more positive associations, Savage argues there has now been a 'dissolution of the working-class as a salient cultural identifier', because organizational shifts have re-positioned manual work as a 'form of subordinate and dependent labour', for men as well as women (Savage, 2000: $148,134)$.

Class dis-identification is itself a class process, since the values which shape people's willingness to identify with class (or not) are themselves class differentiated, arising out of class oppositions and struggles. The absence of direct reference to class in everyday discourse is taken as a sign of class in action, with 'class' now encoded in implicit ways:

'despite a pervasive denial of class status, there are emotional intimacies of class which continue to shape individuals' everyday understandings, attitudes and actions' (Reay, 1998b: 267).

This entails a very different understanding of what 'class' means: fusing status and class elements, with 'class' identity redefined from explicit attachment to a collectivity, to a sense of relational social distance within a hierarchy:

\footnotetext{
'Although a majority of mothers did not mention social class until I asked them to self-identify in class terms, they continually drew on distinctions of "people like us" and "people unlike us" in order to differentiate themselves and others' (Reay, 1998b: 269).

'...while collective class identities are indeed weak, people continue to define their own individual identities in ways which inevitably involve relational comparisons with members of various social classes' (Savage, 2000: xii).
}

This evokes more implicit 'class identities' but, legitimately, argues that 'class' continues to shape people's social identity (even if perceived in highly individualized ways) because class cultures are now viewed as 'modes of differentiation rather than as types of collectivity' (Savage, 2000: 102), a 'social filter and a key mechanism individuals utilize in placing themselves and others' (Reay, 1997: 226). 
The key issue is not self-conscious claims to class identity, but the classed nature of social and cultural practices. Such accounts draw inspiration from Bourdieu's notion that class inequalities are reproduced through the hierarchically differentiated nature of tastes (Bourdieu, 1984, 1985, 1987), which 'owe their special efficacy to the fact that they function below the level of consciousness and language, beyond the reach of introspective scrutiny or control by the will' (1984: 467). For Bourdieu, inequality is reproduced in such simple acts as cultural preferences, 'without those operations ever having to be formulated other than in the socially innocent language of likes and dislikes (1984: 243).

Such distinctions place individuals, and construct not class identities, but rather classed identifications. For Savage, Bourdieu's arguments

\footnotetext{
'...lead not to an emphasis on class as heroic collective agency, but towards class as implicit, as encoded in people's sense of self-worth and in their attitudes to and awareness of others - on how they carry themselves as individuals.... It is hence the very salience of class struggles over distinction which explains why it is so difficult for them to be explicitly named and identified by their protagonists, and to be tied down into a neat model specifying the relationship between social location and culture' (Savage, 2000: 107).
}

The crisis of class identities has resulted in a new focus in class analysis: on class as an individualized process of hierarchical distinction. 'Class' processes have become more implicit and less visible, but the effects of class are no less pervasive in people's lives. This is a radical shift in how class is seen to operate. Rather than the polar terms of 'class in itself' giving rise to 'class for itself' in which inequality triggered consciousness and action, this new model sets out a reverse process, where explicit class identification and awareness dissolve, leaving behind a hierarchical version of 'class', implicitly encoded in identity through practice.

The importance of this theoretical change cannot be over-emphasized, since it offers a fundamentally different way of thinking about how inequality works. However, there are problems in specifying the relationship between these two, very different, aspects of 'class'. 'New' theories of class are still 'captured' by older class categories, albeit in different ways. In some accounts there is a tendency to slip between different meanings of 'class', underestimating the extent of the difference, and the incompatibility, between old and new theoretical frameworks. Other accounts make a stronger distinction between individualized 'class' and collective 'class', but still tend to relate individualized processes to shifts in organizational cultures, downplaying the broader cultural aspects of hierarchy.

\section{Class Analysis in Identity Crisis}

Despite attempts to move beyond the idea of class as collectivity, the assumptions of older forms of class theory re-emerge, and threaten to undermine the important gains made in re-theorizing class as hierarchical. Some accounts still use the language of class conflict and exploitation in ways which sit uncomfortably with the more diffuse and implicit classed processes of culturalist analysis. Class dis-identification is sometimes described as the result of middle-class triumph in the class struggle:

\footnotetext{
'...the advent of 'classlessness' and the lack of collective working-class action can be viewed as the product of a dominant class strategy which has been extremely successful' (Reay, 1998b: 263).
} 
'There was a time when the concept [of class] was considered necessary by the middle classes to maintain and consolidate differences in power: its recent invisibility suggests that these differences are now institutionalized, legitimated and well established' (Skeggs,1997a: 7).

The absence of class identities is taken as evidence of class conflict and exploitation, in a manner reminiscent of older Marxist claims of false consciousness. The use of such language undermines the distinction between older and new meanings of 'class'. Skeggs, for example, argues that 'class is about conflict, power and opposition rather than just sites of differences' (1997b: 134) since classes 'are historically produced constructs developed to consolidate the power of one group at the expense of another' (p. 135), whilst Reay argues that 'the individualistic and self-interested activities of the privileged in society add up to a specific form of collective class action' (Reay, 1998a: 161). But whilst it is legitimate to argue that processes of hierarchical distinction serve to reproduce inequality and advantage in a tacit and individualized manner, it is less legitimate to characterize such processes as class struggle. Class was retheorized as an individualized process partly in response to the lack of overt class conflict or struggle. To now characterize individualized class processes and disidentification as themselves a form of (underground) class 'conflict' entails a considerable broadening in the meaning of class conflict.

Accounts of class dis-identification offer valuable evidence of the way in which processes of cultural distinction help to reproduce inequality. Such theorists are right to argue that implicit processes of hierarchical reproduction are no less important than overt processes of class struggle, and that the effects of 'class' on people's lives have not weakened, even though they may be less visible to the people concerned. However, hierarchical inequality is not, in itself, a form of exploitation, nor can the statements of resentment and contempt between unequals be regarded as 'class conflict'.

Slippage between different meanings of 'class' has opened up such studies to criticism: in particular, to charges that they shore up class analysis by a sleight of hand, substituting weaker evidence of 'class (dis)identity' as proof of 'class' processes. Travers, for example, argues that theorists impose class categories in the teeth of respondents' denials:

'It is perhaps understandable that sociologists whose central problematic is class usually adopt a competitive stance towards common-sense knowledge, since it is hard to find much evidence that members of the working class do understand their lives in class terms' (1998: 6.1).

Travers' frustration is at theory which takes all apparent outcomes - both the avowal and the denial of class - as evidence of 'class' in action. However, his criticism is based on an older model of 'class' - class as explicit, collective identity:

'If... those being studied do not understand their actions in collective terms, or even think of themselves as members of a class, then sociologists should not use the term in describing their activities' (1998: 2.6).

Travers is right to argue that 'class dis-identification' does not amount to evidence of class processes, but only if we take 'class' to mean collectivity. The real problem is that two very different meanings of 'class' are being employed in accounts of class dis-identification class as explicit and collective and class as implicit and hierarchical. Travers recommends a focus on 'the status divisions that people recognize in their everyday lives' (1998: 6.2). 
However accounts of 'class' as an individualized, hierarchical process have just such a focus, although they operate with a much more tacit form of 'recognition', as manifested in social relations. Travers argues that the relevance of class or status divisions 'has to be demonstrated for members of society in actual situations' (10.3), yet this is precisely what 'new' theories of class are attempting to demonstrate.

Theories of class dis-identification argue that hierarchical position acts as a constraint on aspirations, tastes, networks and resources, and that hierarchy is therefore an important element shaping social identity - regardless of whether people are willing to talk about themselves, and others, in explicitly 'class' terms. Shifts in discursive identities do not necessarily undermine classed identifications, with the latter clearly being seen as a prior and more basic form of class process. Such studies are not looking for class consciousness, but rather classed consciousness, in which the recognition of social divisions - or rather social distance - is embedded in practice.

The problem arises when individualized, tacit processes are characterized as class conflict. This is more than a question of the rhetoric of class analysis. The language of class 'conflict' carries within it deeply embedded assumptions of 'class' as oppositional and collective. These assumptions seep into the newer accounts, so that the 'new' concept of class tends to collapse back into the older model. Despite re-working 'class' as relational, tacit and hierarchical (rather than categorical, explicit and collective) there is still a tendency for some accounts to fall back on a polarized view of an oppressed working-class and an exploiting middle-class.

'Class dis-identification' accounts rightly emphasize the way in which 'a sense of place', or the social and cultural distance between differently placed groups, helps to limit both horizons and social networks. Yet this is seen as the result of the pathologization of workingclass culture by middle-class groups in which: 'What remains constant is that it is middleclass standards and members of the middle class who instigate judgements' (Skeggs, 1997b: 132). This is very much an oppositional 'class' account which obscures the fuller implications of 'class' as hierarchical positionality.

Reay and Skeggs follow Bourdieu in contrasting the self-assurance of the middle-class with the unease and discomfort of the working-class. However, such competencies are relative and contextual. By being cast in older 'class' (i.e. middle-class versus working-class) rather than in hierarchical terms, these accounts tend to downplay the double-edged nature of such processes. Sections of the middle-classes also feel cultural shame, discomfort and social reserve in their relations with higher social groups (Power et al., 2003), and fractions of the working-class engage in social distancing with sub-ordinates. These are not specifically 'class' actions, but rather a feature of hierarchical relations per se. Skeggs rightly points out that social distance and cultural difference are as likely to prompt defensive reactions against those above (against 'snobs', the 'hoity toity' etc) as against those below ('slags', the 'common' etc.), but to present this as a product of the middle-class denigration of working-class culture ignores the way in which such reactions occur at every level of the social hierarchies that people inhabit (and reproduce, by such practices). Hierarchies, by their nature, generate feelings of shame, suffering and degradation. Such feelings are, of course, unequally distributed, with the most disadvantaged suffering the most. However, it 
is misleading to characterize this as exploitation, because this masks the routine, mundane, and unobjectionable ways in which such objectionable outcomes occurs.

Reay in her discussion of the classed nature of women's involvement with their children's schooling, highlights the gap between the powerlessness and anxiousness of working-class habitus (in confrontation with the education system) compared to the confidence and certainty of middle-class habitus.

'Acting in their child's best interests' inevitably means middle-class mothers acting simultaneously against the interests of the children of other, less privileged, mothers' (Reay, 1998a: 165).

Reay draws a distinction between intentions and outcomes, but all self-interested activities within a hierarchy tend to reproduce social inequality, so to argue that 'class preferences are simultaneously class exclusions' (1998b: 271) means that all activities (which are not actively abnegating) must be exclusionary. This is not a specifically middle-class exclusion, but rather is a general feature of hierarchical positionality. Of course, the result is 'exclusion' in a sense, but only in the widest and most general sense: that disadvantage continues.

In casting such activities as class conflict or exclusion, theorists of class disidentification have allowed their concern about the inequities of class outcomes to obscure a vital point about the processes which generate them. If hierarchy is so decisive in shaping our opportunities, our lifestyles, and our sense of ourselves and others, why is there not a more a reflexive awareness of it? Part of the reason, as culturalist theorists imply, lies in the nature of hierarchical differentiation itself. The multiple and finely graded nature of the strata in hierarchies often serves to blur boundaries. Southerton's study (2002) of the boundaries of identification in a New Town community, found that narratives of 'us' and 'them' formed on the basis of shared social practices and orientations towards everyday life, confirming that implicit 'classed' identities emerge from the hierarchical distinctions that people routinely make. But whilst such typifications help form categories of 'us', the line between 'us' and 'them' is a notoriously shifting marker, and Southerton also found that subjects embedded within local networks of sociality moved beyond 'generic categorizations' to provide more differentiated distinctions within categories based on their local knowledge.

However, if the fine grading of hierarchical distinction provides an uncertain and shifting basis for collectivity (as opposed to categorization) this is linked to another reason for the 'invisibility' of hierarchy. It is precisely because the activities which serve to reproduce hierarchy are so ubiquitous and mundane that they are often not intended or experienced as conflict or struggle. It is legitimate for 'new' class analysis to down-grade the search for self-conscious class awareness or identity, because social interaction and lifestyle have an orderly and consistent pattern strongly constrained by hierarchy. Thus to the extent that people limit their social interactions with each other we can argue that hierarchy (or 'class') is 'recognized' and acts as an important cultural force in people's lives. However, since such processes are also a crucial component reproducing hierarchy this must affect how we view 'class conflict' and 'exclusion'. A wealth of evidence shows that not merely cultural tastes, but also our most intimate and important social relationships are strongly influenced by hierarchical position. Kinship, friendship and partnership all exhibit a strong patterning by social class and status, and the strength of this pattern has endured over very long periods 
of time (Kalmijn, 1998; Laumann and Guttman, 1966; Prandy and Bottero, 2000; Prandy and Jones, 2001).

The people we are closest to tend to come from a very similar social location to our own, and it appears that our choices are governed both by contiguity and by the social comfort that comes from associating with 'people like us'. But since tastes and interests are hierarchically differentiated, it is hard to see how people in a hierarchy can avoid reproducing inequality, simply by liking the things and people that they like. Since hierarchy is embedded in the most intimate social relationships, and 'social location' and 'culture' are united in the structured nature of everyday social practices, hierarchical practices emerge as 'second nature', unremarkable and ordinary.

The reproduction of hierarchy is carried out every day, by us all, in the most banal and mundane of activities. The results of such activities are the continuation of inequality. But it is because the processes generating this inequality are so often routine that inequality is so hard to eradicate. The nature of hierarchy is such that simply by going about our daily lives social inequalities are mechanically reproduced. It is a mistake to characterize such processes as class conflict or exclusion, because such language looks back to older models of class, and limits the full implications of inequality understood as the outcome of hierarchical social processes.

It has been a longstanding problem for class theory that the asymmetrical distribution of resources tends to worry sociologists more than it worries lay actors, and the apparent legitimacy of inequality (as opposed to exploitation) is a major factor in the reproduction of hierarchy. The identification of inequality, however enduring and stunting it is in the lives of the people who experience it, is quite different from the identification of exploitation. ${ }^{1}$ Very real issues of exploitation and conflict arise from patterns of inequality, but the discussion of such issues must draw on the language of perceived injustice and conflict which emerges from people themselves.

Perceptions of fairness or injustice are usually raised in relation to the processes generating unequal outcomes rather than to inequality per se. Inequality itself often goes unquestioned, which means that feelings of injustice normally arise in relation to the experience of hierarchy as a positioning of moral worth. Given this, it is inevitable that feelings of shame will result, as, at various levels, the relatively advantaged seek to establish, and the relatively disadvantaged seek to deny, the idea that their unequal positions are deserved. Sayer argues that a reluctance to talk about class is because this 'raises issues of the relative worth of individuals' (2002: 1.2) and is a question of moral shame. However, objectionable outcomes are reproduced through such mundane, generalized, activities that the processes generating hierarchy are both less visible and, in themselves, less objectionable. It is hard to storm the barricades over social cliques, snobbery, or the pushiness of middle-class mothers.

This is not to deny the importance of exploitation and conflict as mechanisms reproducing hierarchy and disadvantage, but the tacit reproduction of hierarchy must be distinguished from explicit and self-conscious activities, if only because we need to be able to explain how self-conscious class identities, collective behaviour, and explicit conflict relate to more 
implicit, hierarchical processes. But this is the fundamental question which has bedevilled class analysis: why do explicit class identities, class solidarities and demarcated class boundaries emerge at some times and places and not others?

The way this question is discussed by writers within the framework of new class analysis reveals the continuing legacy of older class models. New class analysis rejects the old model of class-in-itself giving rise to class-for-itself, yet the attempt to explain contemporary discourses of classlessness is most frequently presented as a problem of working-class disidentification. The middle-classes are seen as the site of individualized values so their class dis-identifications are less troubling. It is the working-class which is 'the dog that didn't bark in the night', the background assumption being that the working-class should have a class identity, and that it is disadvantage that creates class identities. But class disidentification is not just a recent problem of the working-classes, it is a related to more general processes of hierarchical position.

The first difficulty is that the evidence of collective working-class identities in the past is comparatively thin. As Savage notes, research into class consciousness in a supposedly more collectivist past, the 1970s, found that 'no clear patterns of class consciousness existed, but rather that different kinds of views were "wheeled on" in different situations' (2000: 27). Even further back, the search for a collective past seems chimerical, with historians suggesting that signs of collectivism in the nineteenth century are better characterized as 'populist' rather than 'class' activities (Calhoun, 1981; Joyce, 1990; Stedman Jones, 1984). Cannadine suggests 'the connection between social vocabularies and social identities is more complex and contingent than is generally recognized', since three models of society ('us and them', hierarchical, and tripartite) have dominated discursive constructions of 'class' in Britain, and 'for much of the time they have easily co-existed in people's minds and imaginations' (1998: 166). It is the hierarchical vision of society ('strongly individualist') which has been 'the most pervasive and persuasive', with collective and more adversarial ways of seeing only emerging at particular times and contexts, often with the explicit politicization of social description (p. 167).

So explicit class identities only emerge in very particular contexts. The question is not why the working-class have relinquished class identifications, but rather why, and under what circumstances, hierarchically differentiated groups adopt explicit class discourses, since this seems more unusual. Why do processes of hierarchical differentiation so rarely give rise to collectivized class identities, or indeed explicit class identities of any kind? In moving towards a 'class as hierarchy' model we have to reject the notion that inequality is automatically recognized by the people who experience it. Whilst hierarchy may be decisive in shaping our experience, key aspects of the way in which it affects our lives often serves to obscure the nature of inequality and to prevent explicit class identities from forming.

\section{Social Distance and Networks}

Class dis-identifications and individualized 'class' identities are not just reflections of pathologized representations of working-class culture (i.e. class oppositions), or of shifts in organizational culture. To understand shifts in class identities we have to look beyond the stigmatization of working-class culture and away from the arena of organizational relations, 
because the hierarchically differentiated nature of social networks can itself serve to render class processes less visible in personal life.

For Savage, the remaking of the culture of individualization (related to shifts in workplace organization) has created 'a society that routinely reproduces social inequality at the same time as deflecting the attention of its key agents sideways rather than upwards and downwards, so making the issue of social inequality largely "invisible" and somehow "uninteresting"' (2000: 159). Once, organizational culture clearly demarcated a collar divide, feeding into wider perceptions of 'class' as oppositional, bounded, and thus into explicit class identities:

\footnotetext{
'One of the striking developments during the twentieth century was the way in which class relations were embedded within organizational forms and boundaries.... This took the form of a set of management structures distant from the world of manual employment, which defined themselves as resting "above" the dirty world of manual work. This imperative led to a peculiarly English determination to symbolically mark off manual from non-manual work and to emphasize the distance between the two forms of employment' (Savage, 2000: 132).
}

Now, Savage argues, newly individualized organizational relations have decoupled class from this 'visible public anchorage' (p. 141) so distinct class identities dissipate because of changes in the workplace. Savage is right to argue that we can relate explicit 'class' identities to forms of boundary erection and maintenance embedded in organizational cultures (such as shopfloor versus management), however, class dis-identification goes beyond organizational structures.

Take, for example, the evidence that people shrug off class labels, locating themself as 'ordinary' or 'middling'. Savage argues that 'people seem keen to invoke a distinction between their personal lives - in which class is rarely seen as a salient issue - and the world "out there", the world of politics, the economy, the media' (2000: 37, 117). As Savage notes, when they speak in personal terms 'People want to belong to a group of ordinary, average types, differentiating from a group above them and below them' (p.116).

Savage seeks 'to ground this populist, anti-elitist culture more fully in work and employment relations, in order to show it has distinctive roots in class relationships' (p. 118). However, claims to being 'ordinary' or 'middling' are strongly related to the hierarchical nature of general social networks, over and above workplace relations. In a six nation study of class identification, Kelley and Evans found a 'middling' self-image: 'holds at all levels of the objective stratification hierarchy. Rich and poor, well-educated and poorly educated, highstatus and low status, all see themselves near the middle of the class system, rarely at the top or bottom' (1995: 166). Their conclusion: 'in all societies... people's subjective class identification is with the middle-classes or just below, with very few people identifying with the top or bottom classes'. The reason is that 'reference-group forces restrict the subjective arena to a narrow range in the middle of the class hierarchy' (p. 166). 'Reference-group forces' refers to the way in which:

'Individuals assess their class location in light of the distribution of education, occupations, authority, and income among the people around them. As a consequence, even very high status people see many others above themselves, and very low status people see others even lower.... This tendency to 
perceive everyone as similar to oneself is reinforced by the tendency for one's spouse and friends to be similar to oneself in education, occupational status and income' (Evans et al., 1992: 465).

Because our personal world is largely filled with people just like us, we tend to think of our social situation as normal and unexceptional, and we therefore see our hierarchical position as 'average' or 'middling'.

'People draw their images of class, particularly the less visible aspects of class, from their experiences among family, friends, and co-workers. Peer groups are mainly homogenous in social status, so people see themselves in the middle of the class hierarchy - this is true of rich and poor, educated and illiterate, worker and boss in all six nations. So strong are these intimate images that they attenuate the objective facts of the social hierarchy' (Kelley and Evans, 1995: 174).

Savage argues that 'Contemporary modes of class awareness do not draw contrasts hierarchically, between those above and below, but they draw the gaze sideways, between yourself and others in similar situations' (2000: 159). The evidence for this is compelling, but relates not just to recent shifts in organizational culture and individualized, egalitarian discourses, but also to general features of how hierarchy affects personal relationships. Many of the processes of everyday life lived within an unequal structure themselves help to undermine a sense of class or, at least, fray the edges in such a manner that clear-cut identities fail to emerge. It is because personal life (friendship, marriage, the people who surround us) is hierarchically ordered that people tend to see themselves as 'ordinary', and thus downplay the significance of hierarchy in their lives. Of course, this is only an aggregate tendency - we sit at the centre of associates from a range of social locations, more or less similar to ourselves, forming a 'normal curve' of hierarchically distributed intimates. Whilst this allows us to make relational comparisons, it is within a limited range, and only serves to normalize our own situation as 'middling', so people are likely to feel that 'class' and class conflict are less significant as a feature of personal identity.

\section{Conclusion}

Skeggs notes that it is the "intimate positioning of myself with "others" that enable me to see differences and feel inequality' (1997b: 132-3). But, ironically, because of the deepseated way in which hierarchy is embedded in personal relationships such differences are likely to perceived in public rather than personal contexts. 'Class' exists 'out there' in the public domain, the arena of politics, the media, the workplace, in our encounters with those socially distant from ourselves (again, normally, in various public contexts, or through stereotyped representations of 'them').

The rise (and fall) of oppositional class cultures and explicit identities is related to the nature of 'class' in public life, particularly to politicized claims and discourses or ideologies of hierarchy and inequality. It is not inequality or hierarchy per se which generate explicit, collective class identities, but rather how, at particular times and with varying success, collective 'class' has been mobilized as an organizing (and dividing) principle: at work and in political life. Such mobilizations are contextual and often fleeting, in part because of the way in which other, general, processes of hierarchy work counter to 'class' processes (in the explicit, collective sense). Particular organizational cultures can throw up sharp breaks in the social contacts, lifestyle, and opportunities of different workers, creating discourses and identifications of an explicitly 'economic' or 'class' kind. Yet, recent history demonstrates, 
such identifications can also dissolve. This is partly because of shifts in organizational cultures, and in politicized discourses, however it also relates to the way in which normal processes of hierarchical differentiation work to obscure the significance of inequality, and limit the application of 'class' discourses in our personal lives.

The meaning of 'class', in academic and popular usage, is notoriously slippery, partly because hierarchy and inequality take on such diverse aspects. Recent debates have introduced important new aspects, but without fully specifying the relations between older and newer elements. 'Class' now refers to a range of quite distinct social processes, some of which appear to work in quite opposite ways. In 'renewing' class analysis to include processes of implicit, individualized differentiation, the newer generation of analysts have created the opportunity to look afresh at how inequality and hierarchy work. At present, this promise is only partially fulfilled. Slippage between different meanings of 'class', and the continuing influence of older models, has meant theorists have been reluctant to address issues of hierarchy itself. For this reason, I think it is more helpful to keep these distinct meanings quite separate. If the term 'class' must be used, it is better to restrict it to those explicitly 'classed' discourses which emerge when organizational cultures, social networks, or politicized representations combine to create perceptions of social identity and social division in specifically 'economic' terms. Individualized and implicit processes of positional inequality are better described as social stratification or hierarchy. But whatever our language, it is important to recognize that issues of hierarchy extend well beyond issues of 'class'.

\section{Acknowledgments}

The author would like to thank Graham Crow, Sarah Irwin, Ellie Lee, Derek McGhee, and the three anonymous referees for their very helpful comments on earlier versions of this paper.

\section{Notes}

1 Marx's concept of exploitation entailed the notion that a dominant group had to control the labour of a subordinate group in order to expropriate their product. Although, under capitalism, this relationship was veiled (by free labour ideology) Marx nonetheless conceived it as a situation of direct subordination, in which one group explicitly had power over another. Shorn of the labour theory of value it is hard to see what 'exploitation' can mean, other than the use of power over others to seize advantage. However, this is very different from the hierarchical relations described in 'culturalist' class analysis, in which some groups have greater resources or opportunities than others, and seek to use that edge to maintain their ascendancy. Such relations can only be described as 'exploitation' by considerably diluting the term. The fact that I have greater advantages than others does not, in itself, mean that I have control or power over them, although it does mean that I have more power and control than they do, and will be better able to achieve my goals than they. But the practice of making use of my advantage is not the same thing as using it over others (even though I will benefit, and they will not). Simple advantage can be converted into the control or use of others, but these behaviours should be carefully distinguished, as they appear to be in 'lay' understandings. A hierarchical system is, by definition, one in which some have less whilst others have more, however it not always the case that some have less because others have more. There are situations in which this is so, but they normally occur in 'zero-sum' situations of power or resources; contemporary stratification - as new class 
theorists point out - is characterized by the diversity of resources positioning individuals. 'Exploitation', in the more limited sense (the use of social position to control or take advantage of unequal others) occurs within systems of hierarchy and inequality, but the latter are not reducible to the former.

\section{References}

Bauman, Z. (1992) Intimations of Postmodernity. London: Routledge.

Beck, U. (1986) Risk Society. London: Sage.

Bottero, W. and K. Prandy (2003) 'Social Interaction Distance and Stratification', British Journal of Sociology 54(2): 177-97.

Bourdieu, P. (1984)[1979] Distinction. London: Routledge \& Kegan Paul.

Bourdieu, P. (1985) 'The Social Space and the Genesis of Groups', Theory and Society 14(6): 723-44.

Bourdieu, P. (1987) 'What Makes a Social Class? On the Theoretical and Practical Existence of Groups', Berkeley Journal of Sociology 32: 1-17.

Calhoun, C. (1981) The Question of Class Struggle: Social Foundations of PopularRadicalism During the Industrial Revolution. Chicago, IL: University of Chicago Press.

Cannadine, D. (1998) Class in Britain. London: Yale University Press.

Crompton, R. (1996) 'The Fragmentation of Class Analysis', British Journal ofSociology 47(1): 56-67.

Crompton, R. (1998) Class and Stratification, 2nd Edition: Cambridge: Polity.

Crompton, R. and J. Scott (2000) 'Introduction: The State of Class Analysis', in R. Crompton, F. Devine, M. Savage and J. Scott (eds) Renewing Class Analysis, pp. 1-15. Oxford: Blackwell. Crook, S., J. Pakulski and M. Waters (1992) Postmodernization. London: Sage.

Devine, F. (1992) 'Social Identities, Class Identity and Political Perspectives', Sociological Review 40(2): 229-52.

Devine, F. (1998) 'Class Analysis and the Stability of Class Relations', Sociology 32(1): 23-42.

Devine, F. and M. Savage (2000) 'Conclusion: Renewing Class Analysis', in R. Crompton, F. Devine, M. Savage and J. Scott (eds) Renewing Class Analysis, pp. 184-99. Oxford: Blackwell. Evans, M.D.R., J. Kelley and T. Kolosi (1992) 'Images of Class: Public Perceptions in Hungary and Australia', American Sociological Review 57(4): 461-82.

Goldthorpe, J. (1996) 'Class Analysis and the Reorientation of Class Theory', British Journal of Sociology 47(3): 481-505.

Goldthorpe, J. and G. Marshall (1992) 'The Promising Future of Class Analysis', Sociology 26(3): 381-400.

Hout, M., C. Brooks and J. Manza (1993) 'The Persistence of Classes in Post-Industrial Societies', International Sociology 8(3): 259-77.

Joyce, P. (1990) Visions of the People. Cambridge: Cambridge University Press.

Kalmijn, M. (1998) 'Intermarriage and Homogamy', Annual Review of Sociology 24: 395-421. Kelley, J. and M.D.R. Evans (1995) 'Class and Class Conflict in Six Western Nations', American Sociological Review 60(2): 157-78.

Laumann, E.O. and L. Guttman (1966) 'The Relative Associational Contiguity of Occupations in an Urban Setting', American Sociological Review 31(2): 169-78.

Marshall, G. (1997) Repositioning Class. London: Sage.

Morris, L. and J. Scott (1996) 'The Attenuation of Class', British Journal of Sociology 47(1): 45-55. 
Pahl, R. (1993) 'Does Class Analysis Without Class Theory Have a Future?', Sociology 27(2): 253-8.

Pakulski, J. and M. Waters (1996) The Death of Class. London: Sage.

Power, S., T. Edwards, G. Whitty and V. Wigfall (2003) Education and the Middle Class. Buckingham: Oxford University Press.

Prandy, K. and W. Bottero (2000) 'Social Reproduction and Mobility in Britain and Ireland in the Nineteenth and Early Twentieth Centuries', Sociology 34(2): 265-81.

Prandy, K. and F.L. Jones (2001) 'An International Comparative Analysis of Marriage Patterns and Social Stratification', International Journal of Sociology and Social Policy 21(4/5/6): 16583.

Reay, D. (1997) 'Feminist Theory, Habitus, and Social Class: Disrupting Notions of Classlessness', Women's Studies International Forum 20(2): 225-33.

Reay, D. (1998a) Class Work. University College London: London.

Reay, D. (1998b) 'Rethinking Social Class: Qualitative Perspectives on Class and Gender', Sociology 32(2): 259-75.

Savage, M. (2000) Class Analysis and Social Transformation. Buckingham: Oxford University Press.

Savage, M., G. Bagnall and B. Longhurst (2001) 'Ordinary, Ambivalent and Defensive: Class Identities in the Northwest of England', Sociology 35(4): 875-92.

Sayer, A. (2002) 'What are you Worth? Why Class is an Embarrassing Subject', Sociological Research Online 7(3) URL: http://www.socresonline.org.uk/7/3/sayer.html

Scott, J. (2000) 'Class and Stratification', in G. Payne (ed.) Social Divisions. Basingstoke: Macmillan.

Skeggs, B. (1997a) Formations of Class and Gender. London: Sage.

Skeggs, B. (1997b) 'Classifying Practices: Representations, Capitals and Recognitions', in P. Mahony and C. Zmroczek (eds) Class Matters, pp. 123-34. London: Taylor and Francis.

Southerton, D. (2002) 'Boundaries of "Us" and "Them": Class, Mobility and Identification in a New Town', Sociology 36(1): 171-93.

Stedman Jones, G. (1984) Languages of Class. Cambridge: Cambridge University Press.

Stewart, A., K. Prandy and R.M. Blackburn(1980) Social Stratification and Occupations. London: Macmillan.

Travers, M. (1999) 'Qualitative Sociology and Social Class', Sociological Research Online 4(1) URL: http://www.socresonline.org.uk/socresonline/4/1/travers.html 